\title{
Does bullying predict suicidal behaviors among in-school adolescents? A cross- sectional finding from Tanzania as an example of a low-income country
}

Festo K. Shayo ${ }^{1,3,4^{*}}$ (i) and Paul S. Lawala ${ }^{2}$

\begin{abstract}
Background: Bullying and suicidal behaviors are a silent public health problem among adolescents. Little is known about the link between bullying and suicidal behaviors in low-income countries such as Tanzania. In the current study, we estimated the prevalence of being bullied and determined its association with suicidal behaviors among in-school adolescents.

Methods: We performed a secondary analysis of the Tanzania Global School-based Student Health Survey (GSHS) conducted in 2014. This was the first nationally representative survey conducted to a sample of 3793 in-school adolescents. The primary independent variable was being bullied, while the outcome variables of interest were suicide ideation and suicide attempt. We used a chi-square $x^{2}$ test for group variables comparisons and multivariate logistic regression for statistical associations between independent and outcome variables. In our analysis, a $p<0.05$ was considered statistically significant at $95 \%$ confidence intervals.

Results: The prevalence of being bullied among 3793 surveyed in-school adolescents was 27.0\%. In an adjusted multivariate regression model, being bullied was independently associated with suicidal ideation and suicide attempt: [AOR; 1.9, 95\% C.I; 1.5-2.4], and [AOR; 3.6, 95\% C.I; 2.9-4.5] respectively, $p<0.001$.

Conclusions: Bullying is prevalent and possibly a potential predictor of suicidal behaviors among in-school adolescents in Tanzania. There is a need for all educational stakeholders: teachers, parents, students, mental health professionals, and policymakers to design a program for mitigating the problem of bullying in schools.
\end{abstract}

Keywords: Adolescents, School bullying, Suicide behaviors, Tanzania, Low-income country

\section{Background}

Bullying in schools has been defined as 'unwanted, aggressive behavior among school-aged children. In due course of time, the behavior is likely repeated and involves a real or perceived imbalance of power [1]. Bullying in schools infringes on the rights of children and adolescents to education and health [2,3]. It has short- and long-term negative impacts on adolescents' development in

\footnotetext{
* Correspondence: festocasmir@gmail.com

${ }^{1}$ Department of Internal Medicine, Muhimbili University of Health and Allied Sciences, P. O Box, 65001 Dar es Salaam, Tanzania

${ }^{3}$ Department of Global Health Entrepreneurship, Division of Public Health, Graduate School of Tokyo Medical and Dental University, 1-5-45 Yushima, Bunkyo-ku, Tokyo 113-8510, Japan

Full list of author information is available at the end of the article
}

terms of physical, social, and psychological well-being [4]. The victims of bullying usually experience a number of problems, such as anxiety and depression; suicide behaviors; poor school attendance and dropout; and poor academic achievement [4-6]. For instance, a study conducted in 42 high-income countries of Europe and North America found that bullying victims were more likely to have poor socioeconomic status, a difficult relationship, and psychiatric disorders [4]. School bullying is one of the silent public health concerns that need a dedicated team of families, educators, health-care professionals, and policy-makers to mitigate $[4,7]$.

In the Tanzania context, bullying ("being bullied") is defined as an act of a person being picked on over and 
over again by an individual or group with more power, either in terms of physical strength or social status [3]. Few case studies conducted in Tanzania have reported the burden of bullying among in-school adolescents. In those studies, the most common type of bullying was physical bullying in the form of hitting, kicking, biting, spitting, pushing, and stilling and threatening using a weapon. Male students than female adolescents were more preferred bullies. Nevertheless, among reported effects of bullying were a poor academic performance, social-emotional disorders, and depression $[2,3]$.

Suicide is the major public health problem in the world accounting for about $6 \%$ of all deaths in young people [8]. There are four components of suicide behaviors, namely suicide ideation, a suicide plan, a suicide attempt, and committing suicide (killing oneself) [9]. Furthermore, bullying, violent behaviors, and psychiatric conditions are known as a risk factors for suicide behaviors among adolescents [10]. About $90 \%$ of children and young adults in the world live in low- and middleincome (LMICs): $75 \%$ of suicide mortality occurs in this region [11].

In 2012 Tanzania had twice as a higher suicide rate than the global average: 24.9 versus 11.4 per 100,000 populations. The suicide rate was 3.5 and 20.7 per 100, 000 populations in the age groups 5-14 years and 1529 years, respectively [9].

Studies in high-income countries have reported a link between bullying and suicidal behaviors among school adolescents. For instance, studies in different parts of the United States of America found that bullied students were significantly more likely to experience suicide ideation, planning, and attempt [12-14]. In Greece, a study found that being bullied was an independent predictor of suicide ideation among adolescents regardless of the presence of psychiatric disorders [15]. Moreover, a study in Korea showed that adolescents who experienced physical and non-physical bullying were significantly three times more likely to attempt suicide than their counterparts [16]. In Africa, two studies have reported the link between suicidal behaviors and school bullying. Studies in the Republic of Benin and Malawi reported that the following factors were associated with the likelihood of suicidal attempts among in-school adolescents; anxiety, loneliness, and being bullied [17, 18].

In Tanzania, information is limited about the national prevalence of bullying and its association with suicidal behaviors among in-school adolescents. A single small scale survey conducted among in-school adolescents in Dar es Salaam city in 2006 reported a prevalence of 7 and $6.3 \%$ for suicidal ideation and suicidal plan, respectively. It was revealed that psychological factors (loneliness and anxiety), and being bullied were among the factors significantly associated with suicidal behaviors
[19]. Although the burden of school bullying in Tanzania has been reported by a few small scale studies, it is less emphasized and underestimated. Therefore, in the current study, we explored the national prevalence of school bullying and its association with suicidal behaviors among in-school adolescents.

\section{Method}

\section{Data source}

In the current study, we did a secondary analysis of the first Tanzania Global School-based Student Health Survey (GSHS) conducted in 2014. The 2014 GSHS was conducted by the Tanzania Ministry of Health and Social Welfare (MoHSW) in collaboration with the Ministry of Education and Vocational Training (MoEVT), under the National School Health Programme (NSHP). World Health Organization (WHO) and the Centre for Diseases Control (CDC) provided financial and technical assistance. The national GSHS Coordinator organized and supervised the survey with strict adherence to the standard GSHS methodology. The dataset for the current analysis was obtained from the WHO public domain: http://www.who.int/ncds/surveillance/gshs/ tanzaniadataset/en/.

\section{Sampling, sample size, and data management}

Tanzania 2014 GSHS used a two-stage cluster sampling to obtain a representative sample of students in primary schools (grade/standard 6-7) and in secondary schools (form 1-3), who corresponds with the GSHS targeted aged range $13-17$ years. The school response rate was $100 \%$, while the student response rate was $87 \%$. Overall, 3797 of the 4373 sampled students completed questionnaires, and 3793 questionnaires were usable after data editing. More details about the methodology can be accessed in the preceded publications [20-22].

\section{Operational definitions}

In the current study, we defined bullying as when a student or group of students say or do bad and unpleasant things to another student. It is also regarded as bullying when a student is teased a lot in an unpleasant way or when a student is left out of things on purpose $[1,3]$.

Suicide behaviors refer to a range of four components behaviors including suicide ideation, suicide planning, suicide attempt, and committing suicide (killing oneself) [13]. In the current study, we defined suicide behaviors based on two components: suicide ideation and suicide attempt.

\section{Study variables \\ Outcome variables}

The primary outcome variables were the suicide ideation and suicide attempt. The study participants were 
categorized into two groups of those who reported suicidal ideation and those who reported a suicide attempt. The variables were obtained from the two questions response of the Tanzania GSHS questionnaire. For suicide ideation, the participants were asked: During the past 12 months, did you ever seriously consider attempting suicide? Responses were Yes and No. For a suicide attempt, the participants were asked: During the past 12 months, how many times did you actually attempt suicide? The response was Yes for 1,2,3,4,5, and $\geq 6$ times attempts and No for zero attempts.

\section{Independent variables}

The primary independent variable was being bullied [3] Participants were asked: During the past 30 days, on how many days were you bullied? The response ranged from zero, $1-2,3-5,6-9,10-19,20-29$, and all 30 days. This was then decoded as Yes for 1 to all 30 days, and No for zero days. The other independent variables were loneliness and anxiety. Regarding loneliness, the participants were asked: During the past 12 months, how often have felt lonely? Responses: never, rarely, sometimes, most of the time, and always. The responses were categorized into Yes (combined most of the time and always) and No (never, rarely, and sometimes). For the Anxiety, the participants were asked: During the past 12 months, how often have you been so worried about something that you could not sleep at night? The responses were categorized into Yes (combined most of the time and always) and No (never, rarely, and sometimes). Also in the current analysis, we have included the following variables gender (male and female), age (categorized into $\leq 12$ yrs., $13-17$ yrs., and $>17$ yrs), and school grade (categorized into primary and secondary school).

\section{Data process and analysis}

We assessed for the pattern of missing data in the GSHS data set and found that the missing data followed a random pattern. Therefore, we used a Full Conditional Specification (FCS) command of multiple imputations to account for the missing data. We found that there was no bias in the results between the imputed dataset and the original dataset: replacing the missing data with imputed data did not make a significant difference. We run five imputations to achieve an efficiency of $>97 \%$. The use of multiple imputations has been reported by previous studies [17, 20-23].

In the current study, we used both descriptive and inferential statistics to present our results. We used a chisquare $X^{2}$ test for group variables comparisons and multivariate logistic regression for statistical associations between independent and outcome variables. In our analysis, a $p<0.05$ was considered statistically significant at
95\% confidence intervals. We used SPSS version 22 (SPSS, Chicago, IL) in the current analysis.

\section{Results}

Demographic characteristics and prevalence of bullying Table 1 represents the demographic characteristics of study participants, prevalence of bullying, suicidal behaviors, and other risk factors. Of the 3793 in-school adolescents, the prevalence of being bullied was $27 \%$ while, $52.1 \%$ of the adolescents were females.

\section{Bullying and suicide behaviors}

Table 2 represents the relationship between suicidal behaviour and being bullied. A significantly large proportion of adolescents with suicidal ideation and attempt had ever been bullied compare to their counterparts: $220(41.0 \%)$ vs. $803(24.7 \%)$, and $238(56.4 \%)$ vs. 785 (23.3\%), respectively.

\section{Factors associated with suicide behaviors Bullying and suicide behaviors}

After adjusting for the potential confounders in the regression model, being bullied remained a significant independent predictor of suicide ideation and attempt: [AOR; 1.9, 95\% C.I; 1.5-2.4], and [AOR; 3.6, 95\% C.I; 2.9-4.5], respectively. For more details, refer to Table 3.

Table 1 Demographics, the prevalence of bullying and suicidal behaviors among in-school adolescent $N=3793$ ]

\begin{tabular}{lll}
\hline Variables & Categories & $\mathrm{n}[\%]$ \\
\hline $\begin{array}{l}\text { Demographics } \\
\text { Gender }\end{array}$ & Male & $1819[47.9]$ \\
& Female & $1974[52.1]$ \\
Age & $\leq 12$ yrs. & $681[18.0]$ \\
& $13-17$ yrs. & $2987[78.7]$ \\
& $>17$ yrs. & $125[3.3]$ \\
Academic level & Primary school & $2085[55.0]$ \\
& Secondary school & $1703[44.9]$ \\
Bullying & Other grade & $5[0.1]$ \\
& Yes & $1023[27.0]$ \\
Loneliness & No & $2770[73.0]$ \\
& Yes & $283[7.5]$ \\
Anxiety & No & $3510[92.5]$ \\
& Yes & $237[6.2]$ \\
Suicide ideation & No & $3556[93.8]$ \\
Suicide attempt & Yes & $536[14.1]$ \\
& No & $3257[85.9]$ \\
& Yes & $422[11.1]$ \\
& No & $3371[88.9]$ \\
\hline
\end{tabular}


Table 2 Comparison between bullying and suicidal behaviors among in-school adolescents $(N=3793)$

\begin{tabular}{|c|c|c|c|c|c|c|c|}
\hline \multirow[t]{2}{*}{ Variables } & \multirow[t]{2}{*}{ Categories } & \multicolumn{3}{|c|}{ Suicide ideation } & \multicolumn{3}{|c|}{ Suicide attempt } \\
\hline & & Yes n[\%] & No n [\%] & $P$ value & Yes n [\%] & No n [\%] & $P$ value \\
\hline \multicolumn{8}{|l|}{ Demographics } \\
\hline \multirow[t]{2}{*}{ Gender } & Male & $271[50.5]$ & $1548[47.5]$ & 0.19 & $192[45.4]$ & $1627[48.2]$ & 0.36 \\
\hline & Female & $265[49.5]$ & $1709(52.5)$ & & $230[54.6]$ & $1744[51.8]$ & \\
\hline \multirow[t]{3}{*}{ Age } & $\leq 12 \mathrm{yrs}$ & $150[27.6]$ & $531[16.4]$ & $<0.001$ & $110[25.6]$ & $571[17.0]$ & $<0.001$ \\
\hline & $13-17$ yrs. & 380 [69.8] & $2607[80.2]$ & & $311[72.3]$ & $2676[79.6]$ & \\
\hline & $>17 \mathrm{yrs}$ & $14[2.6]$ & $111[3.4]$ & & $9[2.1]$ & $116[3.4]$ & \\
\hline \multirow[t]{2}{*}{ School grade ${ }^{\S} N=3748$} & Primary & $315[59.7]$ & $1750[54.3]$ & 0.03 & $262[63.1]$ & $1803[54.1]$ & $<0.001$ \\
\hline & Secondary & $213[40.3]$ & $1470[45.7]$ & & $153[36 \cdot 9]$ & $1530[45.9]$ & \\
\hline \multirow[t]{2}{*}{ Bullied } & Yes & $220[41.0]$ & $803[24.7]$ & $<0.001$ & $238[56.4]$ & $785[23.3]$ & $<0.001$ \\
\hline & No & $316[59.0]$ & 2454 [75.3] & & $184[43.6]$ & $2586[76.7]$ & \\
\hline \multicolumn{8}{|l|}{ Psychological } \\
\hline \multirow[t]{2}{*}{ Loneliness } & Yes & $63[11.7]$ & $220[6.8]$ & $<0.001$ & $74[17.5]$ & $209[6.2]$ & $<0.001$ \\
\hline & No & $474[88.3]$ & $3036[93.2]$ & & $348[82.5]$ & 3162 [93.8] & \\
\hline \multirow[t]{2}{*}{ Anxiety } & Yes & 65 [12.1] & $172[5.3]$ & $<0.001$ & 79 [18.7] & 158 [4.7] & $<0.001$ \\
\hline & No & 471 [87.9] & 3085 [94.7] & & 343 [81.3] & 3213 [95.3] & \\
\hline
\end{tabular}

$\S$ other grades category was not included

\section{Psychological factors and suicidal behaviors}

Adolescents with psychosocial factors: anxiety and loneliness were more likely to have experienced suicidal ideation and attempt than their counterparts. For more details, refer to Table 3.

\section{Demographics and suicide behaviors}

Younger adolescents ( $\leq 12 \mathrm{yrs}$ ) were significantly more likely to have experienced suicidal ideation and attempts than their counterparts. For more details, refer to Table 3.

\section{Discussion}

Our current study found that being bullied was an independent predictor of suicidal ideation and attempt among in-school adolescents. The findings are in support of the previous studies in high-income countries of North America, Europe, and Asia [11-16, 24]. The association between suicidal behaviors and other psychological factors such as loneliness and anxiety in the current study was also comparable to previous studies elsewhere $[4,11,17,18]$. Also, in our current study, we adjusted bullying with other strong predictors of suicidal

Table 3 Multivariate logistic regression of the association between bullying and suicidal behaviors among adolescents ( $N=3793$ )

\begin{tabular}{|c|c|c|c|c|c|}
\hline \multirow[t]{2}{*}{ Variables } & & \multicolumn{2}{|c|}{ Suicide ideation } & \multicolumn{2}{|c|}{ Suicide attempt } \\
\hline & & OR [95\% C.I] & AOR [95\% C.I] & OR [95\% C.I] & AOR $(95 \%$ C.I) \\
\hline \multirow[t]{2}{*}{ Age (yrs) (Ref. > 17 yrs.) } & $\leq 12$ & $\begin{array}{l}2.2[1.2-4.2] \\
p=0.01\end{array}$ & $\begin{array}{l}2.8[1.4-5.5] \\
P=0.003\end{array}$ & $\begin{array}{l}2.4[1.2-4.8] \\
p=0.02\end{array}$ & $\begin{array}{l}2.5[1.2-5.6] \\
p=0.02\end{array}$ \\
\hline & $13-17$ & $1.2[0.7-2.1]$ & $1.4[0.8-2.6]$ & $1.5[0.7-2.9]$ & $1.7[0.8-3.6]$ \\
\hline Age $^{a}$ & & $\begin{array}{l}0.6[0.4-0.7] \\
p<0.001\end{array}$ & $\begin{array}{l}0.5[0.4-0.7] \\
p<0.001\end{array}$ & $\begin{array}{l}0.6[0.5-0.8] \\
p<0.001\end{array}$ & $\begin{array}{l}0.7[0.5-0.9] \\
p=0.002\end{array}$ \\
\hline School grade (Ref. Secondary) & Primary & $\begin{array}{l}1.3[1.0-1.5] \\
p=0.03\end{array}$ & $0.9[0.8-1.2]$ & $\begin{array}{l}1.4[1.2-1.8] \\
p<0.001\end{array}$ & $1.1[0.9-1.5]$ \\
\hline Gender (Ref. Female) & Male & $1.1[0.9-1.4]$ & $\begin{array}{l}1.3[1.0-1.6] \\
p=0.03\end{array}$ & $0.9[0.7-1.1]$ & $0.9[0.8-1.2]$ \\
\hline Bullied (Ref. No) & Yes & $\begin{array}{l}2.1[1.7-2.6] \\
p<0.001\end{array}$ & $\begin{array}{l}1.9[1.5-2.4] \\
p<0.001\end{array}$ & $\begin{array}{l}4.3[3.4-5.3] \\
p<0.001\end{array}$ & $\begin{array}{l}3.6[2.9-4.5] \\
p<0.001\end{array}$ \\
\hline Loneness (Ref. No) & Yes & $\begin{array}{l}1.8[1.3-2.5] \\
p<0.001\end{array}$ & $\begin{array}{l}1.4[1.0-2.0] \\
p=0.04\end{array}$ & $\begin{array}{l}3.2[2.4-4.3] \\
p<0.001\end{array}$ & $\begin{array}{l}1.9[1.3-2.6] \\
p<0.001\end{array}$ \\
\hline Anxiety (Ref. No) & Yes & $\begin{array}{l}2.5[1.8-3.4] \\
p<0.001\end{array}$ & $\begin{array}{l}1.9[1.3-2.6] \\
p<0.001\end{array}$ & $\begin{array}{l}4.7[3.5-6.3] \\
p<0.001\end{array}$ & $\begin{array}{l}2.8[2.0-4.0] \\
p<0.001\end{array}$ \\
\hline
\end{tabular}


behaviors like psychological factors: loneliness and anxiety. The purpose was to see whether being bullied can independently predict the likelihood of suicidal behaviors. Most of the reviewed studies in high-income countries did not consider bullying as an independent predictor of suicidal behaviors, except for the study conducted in Greece [15]. Although psychiatric and psychosocial factors are well-known predictors of suicidal behaviors, our study finding emphasizes that bullying is also a potential predictor of suicidal behaviors among in-school adolescents.

Furthermore, the current study found that near onethird of the in-school adolescents were bullied. The frequency of being bullied ranged from one to more than twelve times in the past 12 months preceding the survey. Moreover, a significantly large proportion of adolescents with suicidal ideation and suicide attempt had ever been bullied, experienced loneliness, anxiety, and were in primary schools. The prevalence of bullying in the current study was lower than studies in North America but higher than studies in Korea and Greece. The differences in the prevalence and burden of bullying across countries have been reported in previous studies elsewhere $[4,5]$. Despite those differences, the hypothesis that bullying is an independent predictor of suicidal behaviors remains indisputable. However, we need further evidence from longitudinal studies to explain the phenomena behind the causal relationship between bullying and suicidal behaviors.

The strength of the current study is based on the following aspects: To our knowledge, this is the first nationally representative study in Tanzania to report the association between bullying and suicidal behaviors in adolescents. Therefore, the current study gave valuable insight to inform the education stakeholders and policymakers about the burden of bullying among in-school adolescents. Moreover, it is a piece of add-on evidence that a burden of school bullying is also prevalent among in-school adolescents in low-income countries, such as Tanzania. Nevertheless, the current study was able to show the independent link between bullying and suicidal behaviors, which were less reported by the previous studies. On the other hand, we used the information of physical bullying available the GSHS dataset file hence reflecting the most form of bullying in the Tanzania context [2,3]. Lastly, the current study used multiple imputations to account for non-response variables (missing data). The purpose was to avoid the possibility of bias findings, interpretation, and representativeness.

The current study had the following limitations: First, the variables suicide attempt and bullying had multiple responses ranging from a single to multiple times events. Therefore, the variation between participants who experienced single suicide events and those experienced multiple events, might not be captured in the current study.
Second, we included only one aspect of bullying: being bullied. This is because of the GSHS dataset file does not contain other aspects of bullying such as perpetrator (bullying others) and victim-perpetrator (both being bullied and bullying others). Nevertheless, the dataset did not categorize the four types of bullying: verbal bullying, social bullying, physical bullying, and cyberbullying. Therefore, our current findings may not give the global status of bullying among in-school adolescents. Third, the use of a single item to represent a broad variable, for instance, anxiety, may not suffice to give an overall implication of our findings. Fourth, the current study included only school-going adolescents, hence the finding may not be generalized to all adolescents.

To our knowledge, we think that bullying prevention requires a joint effort from all education stakeholders including teachers, parents, students, school administrators, policymakers, and the whole society. Therefore, we recommend the following: First, educational stakeholders to design a bullying prevention program in order to reduce the burden of bullying behaviors at school. Second, the ministry of health should campaign about the effects of bullying at school and in the community and on how to mitigate the problem. Furthermore, the problem of surrounding suicidal behaviors happening in the context of bullying shouldn't be made secret. Third, the ministries of Health and Education should collaborate to mitigate the school bullying by endorsing a political will towards the protection of the right for education to all students. Also, the introduction of a new subject about adolescent psychology and behaviors in primary and secondary schools may be helpful to both students and teachers. Lastly, all health professionals who encounter adolescents reporting about bullying should also be curious to know about any background clue of suicidal behaviors and vice versa.

\section{Conclusion}

Similar to high-income countries, our study showed that being bullied is prevalent among in-school adolescents in Tanzania as an example of a low-income country. Moreover, being bullied may be a potential independent predictor of suicidal behaviors. Therefore, it is of paramount importance for educational stakeholders including teachers, parents, students, mental health professionals, and policymakers to design a bullying prevention program at the school level.

\section{Abbreviations \\ AOR: Adjusted odds ratio; C.l: Confidence interval; CDC: Centre for Diseases Control; GSHS: Global School-based Student Health Survey; MoEVT: Ministry of Education and Vocational Training; MoHSW: Ministry of Health and Social Welfare; OR: Odds ratio; WHO: World Health Organization}

\section{Acknowledgments}

We are grateful to the World Health Organization (Geneva) and the Centre for Disease Control and Prevention (USA) for making data available publicly 
for further analysis. We are also thanking the Tanzania ministries of Health and Education, study participants, and study team for making the first nationally representative Tanzania Global School-based Students Health Survey 2014 possible. The World Health Organization and the government of the study country had no influence on the current analysis and decision to publish the current analysis findings.

\section{Authors' contributions}

FKS developed the hypothesis, searched and reviewed the relevant literature, performed data analysis, and interpretation, and wrote the manuscript. PSL developed the hypothesis, searched and reviewed the relevant literature, interpreted the findings, and wrote the manuscript. All authors read and approved the final manuscript.

\section{Funding}

Not applicable to the current study analysis.

\section{Availability of data and materials}

The dataset files used for analysis in the current study are publicly free available in the WHO repository (http://www.who.int/ncds/surveillance/gshs/ tanzaniadataset/en/).

\section{Ethics approval and consent to participate}

The present study was based on an analysis of the Tanzania 2014 GSHS survey dataset freely available online with all identifier information detached. The Tanzania 2014 GSHS was approved by both the Tanzania Ministry of Health and Social Welfare (MoHSW) (currently the Ministry of Health, Community Development, Gender, Elderly and Children /MoHCDGEC) and Ministry of Education and Vocational Training (MoEVT) (currently the Ministry of Education, Science and Technology /MoEST). Therefore, the permission and ethical approval for the present analysis was automatically deemed unnecessary.

Moreover, during the GSHS survey, written assent attached to a questionnaire was obtained from all eligible participants before filling the questionnaire. The survey was designed to protect student confidentiality voluntary participation and anonymous identity. Students were clearly explained that they were free not to participate and also not to respond to any question on the questionnaire.

\section{Consent for publication}

Not applicable for the current analysis.

\section{Competing interests}

The authors declare that they have no competing interests.

\section{Author details}

${ }^{1}$ Department of Internal Medicine, Muhimbili University of Health and Allied Sciences, P. O Box, 65001 Dar es Salaam, Tanzania. 'Department of Psychiatry and Mental Health, Mbeya Zonal Referral Hospital, P.O. Box 419, Mbeya, Tanzania. ${ }^{3}$ Department of Global Health Entrepreneurship, Division of Public Health, Graduate School of Tokyo Medical and Dental University, 1-5-45 Yushima, Bunkyo-ku, Tokyo 113-8510, Japan. ${ }^{4}$ Dar es Salaam, Tanzania.

\section{Received: 21 January 2019 Accepted: 11 December 2019}

Published online: 16 December 2019

\section{References}

1. UN Educational, Scientific and Cultural Organisation (UNESCO), School Violence and Bullying: Global Status Report, 2017. https://www.refworld.org/ docid/587f37154.html. Accessed 22 Nov 2019.

2. Ndibalema P. Perceptions about bullying behaviour in secondary schools in Tanzania : the case of Dodoma municipality. Int j Ed Res. 2013;1(5):1-16.

3. Hyera DM, Kimambo RW, Ole JE. Reducing Child to Child Bullying in Primary Schools in Tanzania, the Case of Kongowe Primary School in Kibaha District; 2009. p. 171-88.

4. World Health Organization. Bullying and physical fights among adolescents. Health Behaviour in School-Aged Children. 2016. http://www.euro.who. int/_data/assets/pdf_file/0005/303485/HBSC-No.7_factsheet_Bullying. pdf?ua=1. Accessed 22 Nov 2019.

5. Gini G, Pozzoli T. Bullied children and psychosomatic problems: a metaanalysis. Pediatrics. 2013;132(4):720-9.
6. Srabstein J, Piazza T. Public health, safety and educational risks assiciated with bullying behaviors in American adolescents. Int J Adolesc Med Health. 2008;20(2):223-34.

7. Srabstein JC, Leventhal BL. Prevention of bullying-related morbidity and mortality: a call for public health policies. Bull World Health Organ. 2010; 88(6):403.

8. Patton GC, Coffey C, Sawyer SM, Viner RM, Haller DM, Bose K, et al. Global patterns of mortality in young people: a systematic analysis of population health data. Lancet. 2009;374(9693):881-92.

9. World Health Organization. Preventing suicide. CMAJ. 2014;143(7):609-10.

10. McKinnon B, Gariepy G, Sentenac M, Elgar FJ. Adolescent suicidal behaviours in 32 low- and middle-income countries. Bull World Health Organ. 2016;94(5):340-350F. https://doi.org/10.2471/BLT.15.163295.

11. Messias E, Kindrick K, Castro J. School bullying, cyberbullying, or both: Correlates of teen suicidality in the 2011 CDC youth risk behavior survey. Compr Psychiatry. 2014;55(5):1063-8. https://doi.org/10.1016/j.comppsych. 2014.02.005.

12. Arango A, Opperman KJ, Gipson PY, King CA. Suicidal ideation and suicide attempts among youth who report bully victimization, bully perpetration and/or low social connectedness. J Adolesc. 2016;51:19-29. https://doi.org/ 10.1016/j.adolescence.2016.05.003.

13. Espelage DL, Holt MK. Suicidal ideation and school bullying experiences after controlling for depression and delinquency. J Adolesc Heal. 2013;53(1 SUPPL):S27-31. https://doi.org/10.1016/j.jadohealth.2012.09.017.

14. Hepburn L, Azrael D, Molnar B, Miller M. Bullying and suicidal behaviors among urban high school youth. J Adolesc Heal. 2012;51(1):93-5. https://doi.org/10.1016/j.jadohealth.2011.12.014.

15. Skapinakis P, Bellos S, Gkatsa T, Magklara K, Lewis G, Araya R, et al. The association between bullying and early stages of suicidal ideation in late adolescents in Greece. BMC Psychiatry. 2011;11(1):22.

16. Roh BR, Yoon Y, Kwon A, Oh S, Lee SI, Ha K, et al. The structure of cooccurring bullying experiences and associations with suicidal behaviors in Korean adolescents. PLoS One. 2015;10(11):1-14.

17. Randall JR, Doku D, Wilson ML, Peltzer K. Suicidal behaviour and related risk factors among school-aged youth in the republic of Benin. PLoS One. 2014;9(2):1-9.

18. Shaikh MA, Lloyd J, Acquah E, Celedonia KL, Wilson ML. Suicide attempts and behavioral correlates among a nationally representative sample of school-attending adolescents in the Republic of Malawi. BMC Public Health. 2016;16(1):1-8. https://doi.org/10.1186/s12889-016-3509-8.

19. Dunlavy AC, Aquah EO, Wilson ML. Suicidal ideation among schoolattending adolescents in Dar es Salaam, Tanzania. Tanzan J Health Res. 2015;17(1):1-9. https://doi.org/10.4314/thrb.v17i1.5.

20. Shayo FK, Kalomo MH. Prevalence and correlates of sexual intercourse among sexually active in-school adolescents: An analysis of five sub-Sahara African countries for the adolescent's sexual health policy implications. BMC Public Health. 2019;19(1):1285. https://doi.org/10.1186/s12889-019-7632-1.

21. Shayo FK. Co-occurrence of risk factors for non-communicable diseases among in-school adolescents in Tanzania: an example of a low-income setting of sub-Saharan Africa for adolescence health policy actions. BMC Public Health. 2019;19(1):972. https://doi.org/10.1186/s12889-019-7320-1.

22. Shayo FK, Lawala PS. Does food insecurity link to suicidal behaviors among in-school adolescents? Findings from the low-income country of subSaharan Africa. BMC Psychiatry. 2019;19(1):1-8. https://doi.org/10.1186/ s12888-019-2212-6.

23. Azeredo CM, Levy RB, Peres MFT, Menezes PR, Araya R. Patterns of healthrelated behaviours among adolescents: A cross-sectional study based on the National Survey of School Health Brazil 2012. BMJ Open. 2016;6(11): e011571.

24. Bhatta MP, Shakya S, Jefferis E. Association of being bullied in school with suicide ideation and planning among rural middle school adolescents. J Sch Health. 2014;84(11):731-8.

\section{Publisher's Note}

Springer Nature remains neutral with regard to jurisdictional claims in published maps and institutional affiliations. 